\title{
De verbodenverklaring en ontbinding van outlaw motorcycle gangs
}

\author{
Mr.J.L.W. Broeksteeg*
}

\begin{abstract}
De rechter heeft recent twee criminele motorclubs, waaronder de Bandidos, verboden en ontbonden. Volgens hem bestaat er een direct verband tussen gedragingen van leden en de werkzaambeid van de vereniging. De cultuur van de motorclub en de daaruit voortvloeiende gedragingen zijn dermate kenmerkend en structureel, dat zij de samenleving kunnen ontwrichten.
\end{abstract}

\section{Inleiding}

Op 20 december 2017 heeft de rechter de Bandidos Motorcycle Club verboden en ontbonden. Op 17 januari 2018 gebeurde hetzelfde met de Broederschap Catervarius, voortkomend uit een motorclub. ${ }^{1}$ Zo'n tien jaar geleden lukte dat niet met de Hells Angels Harlingen en de Hells Angels Amsterdam. Waarom is het nu dan wel gelukt om een criminele motorclub te verbieden?

In dit artikel werk ik deze vraag uit. Ik geef eerst het wettelijk kader weer (par. 2) en vervolgens de jurisprudentie ter zake van de Hells Angels (par. 3). Voor een goed begrip van de recente verbodenverklaring is het nodig een zijsprong te maken naar de jurisprudentie over een ander type vereniging, namelijk de vereniging Martijn (par. 4). Vervolgens analyseer ik de recente verbodenverklaringen van de Bandidos en Catervarius (par. 5) en ten slotte geef ik het recente initiatief van de Tweede Kamer over bestuurlijke verbodenverklaring weer (par. 6).

2 Artikel 2:20 BW: strijd met de openbare orde Artikel 8 van de Grondwet (Gw) legt de vrijheid van vereniging vast. Voor personen betekent het grondrecht de vrijheid om verenigingen te stichten en om er lid (of juist geen lid) van te zijn. Ook rechtspersonen en groepen kunnen zich op het grondrecht beroepen. Beperkingen zijn slechts toegestaan bij de wet - artikel $8 \mathrm{Gw}$ laat geen delegatie toe - en in het belang van de openbare orde. Artikel 2:20 van het Burgerlijk Wetboek (BW) bevat dit doelcriterium om die reden ook: het regelt de verbodenverklaring en ontbinding van rechtsperso-

Mr. J.L.W. Broeksteeg is universitair hoofddocent staatsrecht aan de Radboud Universiteit.

1. Ik ben mij bewust van de open brief van de Koninklijke Nederlandse Motorrijders Vereniging (KNMV), waarin zij stelt dat het woord motorclub een steeds negatievere betekenis krijgt, terwijl er in Nederland zo'n 500 motorclubs zijn, die met de outlaw motorcycle gangs (OMG's) niets van doen hebben. Zie knmv.nl. Omwille van de leesbaarheid gebruik ik hier motorclubs, waarbij telkens de OMG's zijn bedoeld. nen waarvan doel en/of werkzaamheden in strijd zijn met de openbare orde. Dit criterium is beperkter dan strijd met de wet. Volgens de wetgever moet het gaan om 'handelingen die inbreuk maken op de algemeen aanvaarde grondvesten van ons rechtsstelsel'.2 Op welke wijze de jurisprudentie deze open norm interpreteert, behandel ik in de volgende paragrafen.

Artikel 2:20 BW makkt een onderscheid tussen werkzaamheid in strijd met de openbare orde, hetgeen (imperatief) verbodenverklaring en ontbinding van de rechtspersoon tot gevolg heeft (lid 1), en een doel in strijd met de openbare orde, hetgeen leidt tot ontbinding van de rechtspersoon (lid 2). In het laatste geval kan de rechtbank de rechtspersoon in de gelegenheid stellen om zijn doel te wijzigen. Het artikel geeft kort de procedure van verbodenverklaring en ontbinding weer: het Openbaar Ministerie verzoekt de rechtbank daartoe.

De vrijheid van vereniging is ook in mensenrechtenverdragen vastgelegd. In het bijzonder is artikel 11 van het Europees Verdrag tot bescherming van de rechten van de mens en de fundamentele vrijheden (EVRM) van belang en de uitleg die het Europees Hof voor de Rechten van de Mens (EHRM) daaraan geeft. Voor deze bijdrage is van belang dat er weliswaar veel Straatsburgse jurisprudentie bestaat over verboden politieke partijen, maar nauwelijks over 'gewone' verenigingen. Kort weergegeven komt deze jurisprudentie erop neer dat alleen 'convincing and compelling reasons' een beperking van een verenigingsvrijheid kunnen rechtvaardigen. Dat is bijvoorbeeld het geval bij herhaaldelijk en excessief geweldgebruik waarbij de vereniging (bijvoorbeeld een vereniging van voetbalsupporters) direct betrokken is. In ieder geval geldt dat elke beperking van de verenigingsvrijheid proportioneel moet zijn tot het doel van die beperking. ${ }^{3}$

Artikel 2:20 BW is in het verleden niet lichtvaardig toegepast. Sinds de inwerkingtreding van het Nieuw BW in 1992 is, tot de recente verbodenverklaringen, vier keer een rechtspersoon verboden. In 1998 verklaarde de rechter de extreemrechtse politieke partij CP'86 verboden en besloot tot ontbinding van

2. Kamerstukken II $1984 / 85$, 17476 , 5, p. 2-3. Uitgebreid: C.A.J.M. Kortmann, Constitutioneel recht, Deventer: Wolters Kluwer 2016, p. 486 e.v.

3. Uitgebreid: J.L.W. Broeksteeg, Freedom of assembly and association, in: P. van Dijk e.a. (red.), Theory and practice of the European Convention on Human Rights, Antwerpen: Intersentia 2018, p. 828-829. 
de rechtspersoon. Haar werkzaamheden waren volgens de rechter in strijd met de algemeen aanvaarde grondvesten van vrijheid en menselijke waardigheid. Met haar werkzaamheden beoogde de politieke partij niets anders dan discriminatie. ${ }^{4}$ In 2001 werd de Vereniging van Enschedese Cannabisproducenten verboden en ontbonden ${ }^{5}$ en in 2012 trof Euromex Trade $\mathrm{BV}$ hetzelfde lot. ${ }^{6}$ Hierna komt de verboden vereniging Martijn aan bod.

\section{Hells Angels: ontwrichting van de samenleving}

Niet alle pogingen tot verbodenverklaring en ontbinding slaagden. Op 6 maart 2007 gaf de Rechtbank Leeuwarden een beschikking in de zaak van de Hells Angels Harlingen, werkzaam als twee rechtspersonen, namelijk als stichting en vereniging. ${ }^{7}$ De rechtbank stelt vast dat de leden van de vereniging allen een strafblad hebben, de stichting en vereniging softdrugs verkochten en bij een doorzoeking van het clubhuis wapens en munitie werden aangetroffen. Daaruit volgt echter niet dat de stichting en vereniging verboden en ontbonden kunnen worden:

'Het Openbaar Ministerie heeft met de op de Harlinger rechtspersonen betrokken feiten en omstandigheden niet aannemelijk gemaakt dat de werkzaamheid van de stichting en de vereniging zodanig in strijd is met de openbare orde dat daarop alleen met het ultieme middel van verbodenverklaring van de rechtspersonen kan worden gereageerd.'

De rechtbank overweegt onder meer dat het Openbaar Ministerie heeft afgezien van de vervolging van de rechtspersonen:

'Dat de Hells Angels "in georganiseerd verband en op grote schaal ernstige strafbare feiten plegen [die] de grondvesten van ons rechtsstelsel raken en de maatschappij grote schade berokkenen", zoals het Openbaar Ministerie ter zitting heeft betoogd, kan niet op de Harlinger rechtspersonen worden betrokken.'

Het Hof Leeuwarden komt tot een vergelijkbare conclusie, ondanks dat het vaststelt dat de strafbare feiten in voldoende direct verband staan met de stichting en de vereniging. ${ }^{8}$ Het hof komt uiteindelijk 'tot het oordeel dat de gewraakte feiten en omstandigheden betreffende de werkzaamheid van de stichting en de vereniging, voor zover zij komen vast te staan, voor een deel wel kunnen worden aangemerkt als maatschappelijk ongewenst gedrag en mogelijk ook als strafbare feiten, maar niet als een zodanige ernstige inbreuk op de openbare orde dat een verbodenverklaring en ontbinding van een of beide rechtspersonen gerechtvaardigd is'. De Hoge Raad, ten slot-

4. Rb. Amsterdam 18 november 1998, AB 1998/329 m.nt. Kanne.

5. Rb. Almelo 29 augustus 2001, ECLI:NL:RBALM:2001:AD3265.

6. Rb. Amsterdam 1 november 2012, ECLI:NL:RBAMS:2012:BY7450.

7. Rb. Leeuwarden 6 maart 2007, JOR 2007/116 m.nt. Schmieman.

8. Hof Leeuwarden 12 december 2007, ECLI:NL:GHLEE:2007:BB9782. te, volgt 's hofs oordeel. ${ }^{9}$ Het oordeel van het hof omtrent de werkzaamheid van de rechtspersonen geeft geen blijk van een onjuiste rechtsopvatting:

'Voor een verbodenverklaring moet het dan ook gaan om meer dan uit maatschappelijk oogpunt ongewenst gedrag. De verbodenverklaring dient te worden gezien als een noodzakelijke maatregel om gedragingen te voorkomen die een daadwerkelijke en ernstige aantasting vormen van als wezenlijk ervaren beginselen van ons rechtsstelsel en die onze samenleving ontwrichten of kunnen ontwrichten.'

Het hof heeft met recht kunnen vaststellen dat hiervan geen sprake is.

Het verzoek van het Openbaar Ministerie om de Hells Angels Harlingen te verbieden en te ontbinden stond niet op zichzelf. Tegelijkertijd met het hiervoor behandelde verzoek deed het Openbaar Ministerie dezelfde verzoeken voor andere 'chapters' van de Hells Angels. In alle gevallen stelt de rechter echter vast dat geen sprake is van een werkzaamheid die een daadwerkelijke aantasting vormt van de beginselen van ons rechtsstelsel, waarop slechts een verbodenverklaring kan volgen. ${ }^{10}$ Zelfs in het geval van de Hells Angels Nomad (te Oirsbeek), waarbij in het clubhuis een drietal moorden was gepleegd, volgde geen verbodenverklaring, omdat geen sprake was van een structureel patroon van werkzaamheden in strijd met de openbare orde. ${ }^{11}$

\section{Martijn: een EVRM-toets}

Uit de hiervoor besproken rechterlijke beschikkingen komt naar voren dat de vrijheid van vereniging een terughoudende toepassing van artikel 2:20 BW impliceert. De verbodenverklaring van een rechtspersoon is daarmee ultimum remedium. In de zaak Martijn lijkt de rechter een andere benadering te kiezen. Hoewel het geen motorclub betreft, is de zaak van belang, omdat de Hoge Raad hierin een ruimere uitleg van artikel 2:20 BW accepteert.

Martijn is een (formele) vereniging van pedoseksuelen. Het Openbaar Ministerie verzoekt tot verbodenverklaring en ontbinding, omdat de vereniging kinderen, een kwetsbare groep, in hun lichamelijke, emotionele en seksuele integriteit aantast. De Rechtbank Assen willigt het verzoek in. ${ }^{12} \mathrm{Zij}$ stelt vast dat het streven naar seksueel contact met kinderen 'een ernstige inbreuk vormt op de geldende formele waarden binnen onze

9. HR 26 juni 2009, NJ 2009/396 m.nt. Van Schilfgaarde, JOR 2009/222 m.nt. Schmieman.

10. Zie bijv. Rb. Amsterdam 11 april 2007, ECLI:NL:RBAMS: 2007:BA2747 (Hells Angels Holland); Rb. Amsterdam 11 april 2007, ECLI:NL:RBAMS:2007:BA2761, in hoger beroep: Hof Amsterdam 10 april 2008, ECLI:NL:GHAMS:2008:BC9212 (Hells Angels Amsterdam).

11. Rb. Maastricht 29 mei 2007, ECLI:NL:RBMAA:2007:BA5843, in hoger beroep: Hof 's-Hertogenbosch 25 april 2008, JOR 2008/155 m.nt. Schmieman (Hells Angels Nomad).

12. Rb. Assen 27 juni 2012, JB 2012/194 m.nt. Sillen, JOR 2012/316 m.nt. Schmieman. 


\section{Maandblad}

Ondernemingsrecht

samenleving en daarom indruist tegen onze rechtsorde'. De werkzaamheid van de vereniging maakt inbreuk op 'de algemeen aanvaarde grondvesten van ons rechtsstelsel' en is daarmee in strijd met de openbare orde. Opvallend in deze beschikking is dat de rechtbank niet ingaat op het door de Hoge Raad in de Hells Angels-beschikking gegeven criterium van een 'daadwerkelijke en ernstige aantasting' van beginselen van ons rechtsstelsel, waardoor de samenleving wordt ontwricht.

Het hof doet dat in hoger beroep wel. ${ }^{13}$ Het stelt weliswaar vast dat de werkzaamheid van de vereniging een daadwerkelijke en ernstige aantasting vormt van - kort weergegeven - de lichamelijke en seksuele integriteit van het kind, maar dat artikel 2:20 BW niet de belangen van het kind, maar die van de samenleving beoogt te beschermen. Bovendien vormt de werkzaamheid van de vereniging geen bedreiging voor de samenleving; van maatschappelijke ontwrichting of de dreiging daarvan is geen sprake.

De Hoge Raad kiest de lijn van de rechtbank. ${ }^{14}$ Hij besteedt in zijn beschikking veel aandacht aan het EVRM en onderzoekt of de verbodenverklaring en ontbinding voldoen aan de beperkingssystematiek van artikel 11 EVRM: ${ }^{15}$

'Het hof had (...) moeten onderzoeken of het verbod en de ontbinding van de vereniging in een democratische samenleving noodzakelijk zijn in het belang van de bescherming van de gezondheid of de openbare orde of de bescherming van de rechten en vrijheden van anderen.'

Dat heeft het hof niet gedaan en daarom kan zijn beschikking geen stand houden. De Hoge Raad doet vervolgens de zaak zelf af en maakt een belangenafweging tussen de werkzaamheid van de vereniging en de bedreiging daarvan voor de openbare orde enerzijds en de vrijheid van vereniging anderzijds. Hij laat het eerste belang zwaarder wegen, waardoor de vereniging Martijn verboden is verklaard en ontbonden is.

De redenering van de Hoge Raad komt nauw overeen met de toetsingssystematiek van het EHRM. Hij toetst aan de doelcriteria van artikel 11 EVRM en makt vervolgens de belangenafweging op de wijze waarop het EHRM dat in zijn jurisprudentie ook doet. Artikel $8 \mathrm{Gw}$ en artikel 2:20 BW spelen nauwelijks een rol. In mijn annotatie was ik kritisch op deze werkwijze, omdat de Straatsburgse toets altijd subsidiair is: het EHRM reageert op (in casu) verbodenverklaringen naar nationaal recht en geeft, kort gezegd, alleen weer wat de bandbreed-

13. Hof Arnhem-Leeuwarden 2 april 2013, JOR 2013/134 m.nt. Bulten.

14. HR 18 april 2014, NJ 2014/507 m.nt. Alkema, AB 2014/348 m.nt. Brouwer en Molier, JOR 2014/227 m.nt. Bulten, JB 2014/104 m.nt. Broeksteeg, AAe 2014, AA20140834 m.nt. Schutgens.

15. De Hoge Raad betrekt ook het Verdrag van Lanzarote inzake de bescherming van kinderen tegen seksuele uitbuiting en seksueel misbruik en de Richtlijn 2011/92/EU ter bestrijding van seksueel misbruik en seksuele uitbuiting van kinderen en kinderpornografie in zijn oordeel. te is waarbinnen de Nederlandse rechter mag functioneren (margin of appreciation). De EHRM-jurisprudentie is niet bedoeld en leent zich niet voor rechtstreekse toepassing op nationaal niveau.

Hoe dan ook, vergeleken met de Hells Angels-beschikking lijkt de Hoge Raad een nieuwe, meer rekkelijke lijn te hebben uitgezet. Het hof volgde nauwgezet de redenering van de Hells Angels-beschikking en legde daarbij de nadruk op de daadwerkelijke en ernstige ontwrichting van de samenleving. Het constateerde dat de samenleving voldoende weerbaar is tegen de werkzaamheid van de vereniging Martijn. De Hoge Raad kiest een andere insteek: het verbod is noodzakelijk in het belang van de bescherming van de gezondheid, de openbare orde of de rechten en vrijheden van anderen. Hij geeft weer dat de daadwerkelijke ontwrichting van de samenleving geen noodzakelijke voorwaarde is. De Hoge Raad maakt immers een (gemotiveerde) belangenafweging, maar in de rechtsoverwegingen waarin hij de zaak zelf afdoet, onderzoekt hij niet (en zeker niet expliciet) of de werkzaamheden van Martijn de samenleving kunnen ontwrichten. Met het loslaten van de voorwaarde van de daadwerkelijke ontwrichting en de afdoening van de zaak op grond van de belangenafweging lijkt de Hoge Raad een soepelere maatstaf te hebben gegeven.

\section{Bandidos en Catervarius: terug naar ontwrichting}

Wij komen terug bij de criminele motorclubs, namelijk de verbodenverklaring en ontbinding van de Bandidos - om precies te zijn de informele vereniging Bandidos Motorcycle Motorclub (Nederlandse afdeling) en de buitenlandse coöperatie met dezelfde naam (hierna: BMC) - en van Broederschap Catervarius, een informele vereniging die voortkomt uit de traditie van motorclubs.

De Bandidos-beschikking van de Rechtbank Midden-Nederland is zeer uitgebreid gemotiveerd. ${ }^{16} \mathrm{Na}$ wat inleidende beschietingen over de vraag of BMC als wereldwijde vereniging en als informele Nederlandse vereniging wel bestaat, welke vragen de rechtbank bevestigend beantwoordt omdat BMC, kort gezegd, als eenheid naar buiten treedt en er een organisatorisch verband is, komt de rechtbank toe aan de vraag of de werkzaamheid in strijd is met de openbare orde. Opvallend is dat de rechtbank weer teruggrijpt naar de criteria van 'een daadwerkelijke en ernstige aantasting (...) van als wezenlijk ervaren beginselen van ons rechtsstelsel' en 'die onze samenleving ontwrichten of kunnen ontwrichten'. De rechtbank geeft weer op welke wijze de Bandidos zijn georganiseerd en gaat in op de verenigingscultuur. De Bandidos dragen een outlaw-cultuur uit en handelen daar ook naar. Zij plegen ernstige strafbare feiten. De vereniging stimuleert dat door de beloning daarvan met onderscheidingen (patches) en stijging in rang. Tegen uitgetreden leden wordt geweld gebruikt en derden worden bedreigd en afgeperst. Het Openbaar Ministerie heeft daarvan veel voorbeelden gegeven - de rechtbank

16. Rb. Midden-Nederland 20 december 2017, AB 2018/60 m.nt. Brouwer en Koornstra. 
spreekt van een 'overvloed van informatie'. Hoewel het gaat om gedragingen van leden en BMC daar niet direct bij betrokken was, meent de rechtbank dat de cultuur waarin (ernstig) geweld wordt gestimuleerd, de invloed vanuit sommige 'rangen' binnen de vereniging en het gebruik van de naam Bandidos om woorden en daden kracht bij te zetten, betekenen dat het handelen van de leden kan worden toegerekend aan BMC. En ook al zijn niet alle leden van de Bandidos bij ernstige strafbare feiten betrokken, de cultuur en de daaruit voortvloeiende gedragingen zijn dermate kenmerkend en structureel, dat er een reële kans bestaat dat leden geweldsdelicten gaan plegen, die de lichamelijke integriteit van leden en van personen daarbuiten ernstig aantasten en die de Nederlandse samenleving ontwrichten of kunnen ontwrichten. Daarin vindt, aldus de rechtbank, het verbod zijn rechtvaardiging. Het is daarom in een democratische samenleving noodzakelijk dat voor recht wordt verklaard dat de werkzaamheid van BMC in strijd is met de openbare orde en dat BMC (Holland) wordt verboden en ontbonden, 'in het belang van de rechten en vrijheden van degenen die zich in de Nederlandse samenleving bevinden'.

Een maand later verbiedt en ontbindt dezelfde rechtbank, overigens in een aanzienlijk kortere beschikking, het broederschap Catervarius, opgericht in 2015. ${ }^{17}$ Het was eerst een chapter van de vereniging Alcatraz Wanted. Volgens de rechtbank is Catervarius 'een zogenoemd broederschap, voortkomend uit de traditie van motorclubs', wat dat ook precies moge betekenen. Ook Catervarius is een informele vereniging: zij treedt als entiteit in een gecoördineerde vorm met een onderlinge taakverdeling naar buiten, er zijn leden en een bestuur, zij neemt deel aan het rechtsverkeer, enzovoort. De leden van Catervarius zijn onderwerp geweest van verschillende strafrechtelijke onderzoeken, die betrekking hebben op bijvoorbeeld afpersing, geweldpleging, drugsmisdrijven en wapenmisdrijven. Een aantal misdrijven is gepleegd in het clubhuis. Een groot deel van het bestuur zit lange gevangenisstraffen uit. Het Openbaar Ministerie is daarom van mening dat de werkzaamheid van de vereniging in strijd is met de openbare orde en de samenleving ontwricht en dreigt nog verder te ontwrichten. De rechtbank volgt het Openbaar Ministerie en benadrukt, in navolging van de Bandidos-beschikking, de kenmerkende en structurele cultuur van de vereniging en de feitelijk daaruit voortvloeiende gedragingen van de leden, die zeer waarschijnlijk weer ernstige delicten zullen plegen en daarmee de Nederlandse samenleving ontwrichten of kunnen ontwrichten. De leden maken zich in groepsverband schuldig aan de strafbare feiten en beroepen zich op hun lidmaatschap. De gedragingen kunnen daarom, aldus de rechtbank, aan de rechtspersoon als eigen werkzaamheid worden toegerekend.

De beschikkingen van de Rechtbank Midden-Nederland houden het midden tussen de Hells Angels-beschikking en de Martijn-beschikking, maar lijken uiteindelijk toch het meeste op de eerstgenoemde beschikking. De rechtbank stelt het ont-

17. Rb. Midden-Nederland 17 januari 2018, ECLI:NL:RBMNE:2018:113. wrichtingscriterium duidelijk centraal. De toets aan artikel 11 EVRM is vervolgens secundair aan die aan artikel 2:20 BW. Deze benadering lijkt mij juridisch zuiverder dan die van de Hoge Raad in de Martijn-beschikking: eerst komt de beoordeling naar nationaal recht, secundair de EVRM-toets. Waarom komt de rechtbank nu dan wel tot verbodenverklaring en ontbinding van de motorclubs, terwijl dat bij de Hells Angels met toepassing van dezelfde criteria niet lukte? In dat geval kon het Openbaar Ministerie de gedragingen van de leden van de Hells Angels niet koppelen aan de vereniging: deze gedragingen konden niet als eigen werkzaamheid van de Hells Angels worden gezien. Dat is nu wel het geval, omdat het Openbaar Ministerie kon aantonen dat - kort gezegd - de cultuur van de Bandidos en Catervarius gedragingen van de leden tot gevolg had. En hoewel de rechtbank er in beide beschikkingen niet veel aandacht aan besteedt, is thans ook de ontwrichting van de samenleving eenvoudiger te bewijzen. Het aantal criminele motorclubs is gegroeid, er heerst een grote onderlinge rivaliteit (bijvoorbeeld tussen de Bandidos en de Hells Angels) en de sfeer van angst zaaien en gewelddreiging is niet meer beperkt tot (de leden van) de vereniging zelf.

Wat is nu dan de stand van zaken voor motorclubs? In de eerste plaats geldt dat indien (voormalige) leden deelnemen aan de voortzetting van de werkzaamheid van de (verboden) vereniging, zij strafrechtelijk kunnen worden vervolgd op grond van artikel 140 lid 2 van het Wetboek van Strafrecht $(\mathrm{Sr}) .^{18}$ Daarnaast hebben de Bandidos bekendgemaakt in hoger beroep te gaan ${ }^{19}$ - de enige rechtshandeling die de vereniging nog kan verrichten. De procesgang is dus nog niet geëindigd. En ten slotte heeft het Openbaar Ministerie om de verbodenverklaring en ontbinding verzocht van motorclub Satudarah. ${ }^{20}$

\section{Initiatiefwetsvoorstel bestuurlijke verbodenverklaring}

De wetgever heeft in de tussentijd niet stilgezeten. In maart en april 2018 lag een initiatiefwetsvoorstel voor ter internetconsultatie. ${ }^{21}$ Met het voorstel willen de initiatiefnemers mogelijk maken dat de minister (voor Rechtsbescherming) bij beschikking een rechtspersoon kan verbieden en ontbinden indien zijn werkzaamheid in strijd is met de openbare orde (art. 2 lid 1). Het betreft derhalve een bestuursrechtelijk besluit. ${ }^{22}$ Arti-

18. Zie over de samenhang van art. 2:20 BW en art. 140 Sr A.N. Kesteloo, Aanmerken als 'criminele organisatie' een (anvullende) voorwaarde voor verbieden en ontbinden van rechtspersonen?, DD 2016/55.

19. Nos.nl 22 december 2017. Naar verluidt is Catervarius niet in beroep gegaan.

20. Trouw 3 januari 2018

21. Voorstel van wet van de leden Kuiken (PvdA), Van Toorenburg (CDA), Van Oosten (VVD), Van der Graaf (CU) en Van der Staaij (SGP) houdende regels betreffende het bestuursrechtelijk verbieden van rechtspersonen waarvan de werkzaamheid in strijd is met de openbare orde (Wet bestuurlijk verbod rechtspersonen).

22. Daarbij kan de notaris wellicht - de initiatiefnemers noemen dit niet een soort poortwachtersfunctie vervullen. Hij stelt de statuten op en kan beoordelen of het doel van de rechtspersoon in strijd is met de openbare orde. Hij kan de statuten onder de aandacht van de minister brengen. 


\section{Maandblad}

Ondernemingsrecht

kel 2 lid 2 bepaalt dat gedragingen van de leden aan een rechtspersoon worden toegerekend, indien deze gedragingen:

a. samenhangen met de werkzaamheid of het doel van de rechtspersoon;

b. hebben plaatsgevonden in georganiseerd verband; en

c. door de rechtspersoon worden geduld.

De bepaling is, gezien haar redactie én de uitleg in de memorie van toelichting, limitatief bedoeld. Artikel 3 bevat een uitzondering voor politieke partijen. Voor deze rechtspersonen geldt dat alleen de rechter bevoegd is tot verbodenverklaring en ontbinding. Dat is logisch, omdat de minister - lid van een politieke partij - immers vooringenomen kan zijn (art. 2:4 van de Algemene wet bestuursrecht (Awb)). Het voorstel bevat verder voorschriften over de vereffening van het vermogen en specifieke bepalingen over corporaties.

Opvallend is dat het wetsvoorstel neutraal is geformuleerd ('rechtspersonen'), terwijl de initiatiefnemers in de memorie van toelichting uitgebreid ingaan op de outlaw motorcycle gangs. De criminele motorclubs zijn, zo geven zij weer, de aanleiding voor het wetsvoorstel. $\mathrm{Zij}$ menen - kort weergegeven dat de huidige procedure te lang duurt en dat de jurisprudentie te strikt is in de toerekening van gedragingen van leden aan de rechtspersoon. Het is de vraag in hoeverre deze argumenten steekhoudend zijn in het licht van de Bandidos- en Catervarius-beschikkingen. In de eerste plaats de duur: in het geval van de Bandidos duurde het een jaar voordat het ingediende verzoekschrift leidde tot een verbod. Daar kunnen met hoger beroep en cassatie nog wel wat jaren bij komen. De bestuursrechtelijke dossieropbouw en de voorbereiding van het besluit zullen inderdaad korter duren. Tegen het besluit staan echter bezwaar en beroep open. ${ }^{23}$ Met de behandeling van bezwaar, beroep en hoger beroep zal de voorgestelde procedure uiteindelijk niet veel korter duren. Daarenboven gaat het hier om een vergaande beperking van een grondrecht, zodat verdedigbaar is dat een procedure (direct) voor de rechter meer voor de hand ligt. Eventueel tijdverlies moet dan voor lief worden genomen. In de tweede plaats de toerekening: de initiatiefnemers beroepen zich op de Hells Angels-beschikking. Daarin slaagde het Openbaar Ministerie er niet in de rechter ervan te overtuigen dat de gedragingen van leden van de motorclub aan de rechtspersoon toegerekend moeten worden. De initiatiefnemers noemen de Bandidos- en Catervarius-beschikkingen echter niet, waarin dat wel lukte. Ook de door de initiatiefnemers geformuleerde criteria verschillen uiteindelijk niet wezenlijk van de criteria die de rechter in de Bandidos- en Catervarius-beschikkingen toepaste. Daarin ging het immers om een structurele en kenmerkende verenigingscultuur, waardoor de leden hun criminele gedragingen konden plegen. Het is natuurlijk wel nog de vraag of de Bandidos-beschikking standhoudt in hoger beroep.

23. De minister zou de bevoegdheid (in ieder geval theoretisch) ook voor electoraal gewin kunnen gebruiken. Daarom is een rechterlijke toets belangrijk.
Ten slotte: de initiatiefnemers laten zich niet over de vraag uit of artikel 2:20 BW nog bestaansrecht heeft, mocht hun voorstel ooit kracht van wet krijgen. Het ligt voor de hand dat artikel 2:20 BW minder zal worden toegepast. ${ }^{24}$ Het is nochtans opvallend dat het voorstel geen aandacht besteedt aan de verhouding tussen het verbod door de minister en het verbod door de rechter op grond van artikel 2:20 BW. Het is bijvoorbeeld de vraag welke procedure voorrang heeft, indien zij gelijktijdig worden toegepast. Moet de minister een beslissing van de rechter op het verzoek van het Openbaar Ministerie afwachten? Mag hij de beslissing juist wel of juist niet nemen, zolang een verzoek onder de rechter is? Het wetsvoorstel én de memorie van toelichting zwijgen over (de juridische gevolgen van) samenloop met artikel 2:20 BW. Weliswaar kan deze samenloop in de praktijk worden opgelost door werkafspraken tussen de minister en het Openbaar Ministerie, maar het zou toch goed zijn als de initiatiefnemers hieraan aandacht besteden.

\section{Conclusie}

Uit het voorgaande volgt dat het initiatiefwetsvoorstel nog de nodige vragen oproept. Is het voorstel daadwerkelijk nodig om criminele motorclubs aan te pakken? Het antwoord op deze vraag zal mede afhangen van het hoger beroep en de eventuele cassatie in de Bandidos-zaak. De verbodenverklaring en ontbinding van Bandidos zijn, vanwege het ingestelde hoger beroep, nog niet onherroepelijk geworden. Dat lijkt mij echter een kwestie van tijd. De motivering van de rechtbank is zeer uitgebreid en wat mij betreft overtuigend, meer dan die van de Hoge Raad in de Martijn-zaak. De beschikking laat zien dat er een direct verband is tussen de gedragingen van de leden en de werkzaamheid van de vereniging. Dat kon het Openbaar Ministerie in de Hells Angels-zaak niet bewijzen. In de tussentijd lijken de motorclubs in kwestie crimineler te zijn geworden, is de cultuur van angstzaaien, afpersing en onderlinge rivaliteit gegroeid én is er over criminele motorclubs en hun leden meer bekend. Dat makt kennelijk dat het nu wel is gelukt om een motorclub te verbieden, terwijl dat tien jaar geleden nog een brug te ver was.

24. Met dien verstande dat het wetsvoorstel de politieke partijen uitzondert. 